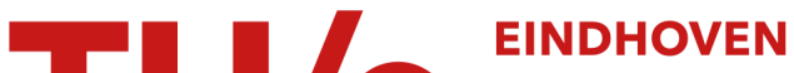 UNIVERSITY OF TECHNOLOGY
}

\section{Remote plasma ALD of SrTiO3 using cyclopentadienlyl-based $\mathrm{Ti}$ and Sr precursors}

\section{Citation for published version (APA):}

Langereis, E., Roijmans, R. F. H., Roozeboom, F., Sanden, van de, M. C. M., \& Kessels, W. M. M. (2011). Remote plasma ALD of SrTiO3 using cyclopentadienlyl-based Ti and Sr precursors. Journal of the Electrochemical Society, 158(2), G34-G38. https://doi.org/10.1149/1.3522768

DOI:

10.1149/1.3522768

Document status and date:

Published: 01/01/2011

\section{Document Version:}

Publisher's PDF, also known as Version of Record (includes final page, issue and volume numbers)

\section{Please check the document version of this publication:}

- A submitted manuscript is the version of the article upon submission and before peer-review. There can be important differences between the submitted version and the official published version of record. People interested in the research are advised to contact the author for the final version of the publication, or visit the $\mathrm{DOI}$ to the publisher's website.

- The final author version and the galley proof are versions of the publication after peer review.

- The final published version features the final layout of the paper including the volume, issue and page numbers.

Link to publication

\section{General rights}

Copyright and moral rights for the publications made accessible in the public portal are retained by the authors and/or other copyright owners and it is a condition of accessing publications that users recognise and abide by the legal requirements associated with these rights.

- Users may download and print one copy of any publication from the public portal for the purpose of private study or research.

- You may not further distribute the material or use it for any profit-making activity or commercial gain

- You may freely distribute the URL identifying the publication in the public portal.

If the publication is distributed under the terms of Article 25fa of the Dutch Copyright Act, indicated by the "Taverne" license above, please follow below link for the End User Agreement:

www.tue.nl/taverne

Take down policy

If you believe that this document breaches copyright please contact us at:

openaccess@tue.nl

providing details and we will investigate your claim. 


\title{
Remote Plasma ALD of $\mathrm{SrTiO}_{3}$ Using Cyclopentadienlyl-Based Ti and Sr Precursors
}

\author{
E. Langereis, ${ }^{*}$ R. Roijmans, F. Roozeboom, * \\ M. C. M. van de Sanden, and W. M. M. Kessels*,z \\ Department of Applied Physics, Eindhoven University of Technology, 5600 MB Eindhoven, The \\ Netherlands
}

\begin{abstract}
Remote plasma atomic layer deposition (ALD) of $\mathrm{SrTiO}_{3}$ films with different $[\mathrm{Sr}] /[\mathrm{Ti}]$ ratios is reported, employing $\mathrm{Star}-\mathrm{Ti}$ [(pentamethylcyclopentadienyl)trimethoxy-titanium, $\left.\left(\mathrm{CpMe}_{5}\right) \mathrm{Ti}(\mathrm{OMe})_{3}\right]$ and Hyper-Sr [bis(trisisopropylcyclopentadienyl)strontium with 1,2-dimethoxyethane adduct, $\left.\operatorname{Sr}\left({ }^{i} \mathrm{Pr}_{3} \mathrm{Cp}\right)_{2} \mathrm{DME}\right]$ precursors and $\mathrm{O}_{2}$ plasma. The as-deposited films were amorphous, but crystallized after post-deposition anneal above $500^{\circ} \mathrm{C}$. For annealed $\mathrm{SrTiO}_{3}$ films with $[\mathrm{Sr}] /[\mathrm{Ti}]=1.3$ and a thickness of $50 \mathrm{~nm}$, a high dielectric constant $k>80$ and low leakage current of $\sim 10^{-7} \mathrm{~A} / \mathrm{cm}^{2}$ at $1 \mathrm{~V}$ were obtained. It is demonstrated that changes in the composition and microstructure are apparent in the optical dielectric function of the $\mathrm{SrTiO}_{3}$ films, as obtained by spectroscopic ellipsometry.
\end{abstract}

(C) 2010 The Electrochemical Society. [DOI: 10.1149/1.3522768] All rights reserved.

Manuscript submitted August 6, 2010; revised manuscript received November 5, 2010. Published December 20, 2010.

Next-generation dynamic random access memories with an equivalent oxide thickness $($ EOT $) \leqslant 0.35 \mathrm{~nm}$ (Refs. 1 and 2$)$, and high-density metal-insulator-metal (MIM) capacitors with specific capacitance $>500 \mathrm{nF} / \mathrm{mm}^{2}$ for automotive and decoupling applications, require ultrahigh permittivity dielectric films (preferentially, $k>100)$ that are conformally deposited in high-aspect ratio structures. Among the perovskite oxide materials with their high dielectric constant for the crystalline films, ${ }^{3,4}$ strontium titanate $\left[\mathrm{SrTiO}_{3}\right.$ (STO), bulk $k \sim 300$, Ref. 3] is of particular interest because of its relatively low crystallization temperature between 500 and $600^{\circ} \mathrm{C}$ (Ref. 5) which is compatible with the process integration schemes limited to a maximum temperature of $600{ }^{\circ} \mathrm{C}$. ${ }^{4}$ Due to the stringent requirements on the conformality of $>95 \%$ step coverage for aspect ratios $>20-30$, targeted thickness of 5-50 nm, and low process temperature, atomic layer deposition (ALD) is considered as the method of choice for the synthesis of these $\mathrm{SrTiO}_{3}$ films for such MIM capacitors [requirements formulated by MaxCaps Consortium including Air Liquide, Aixtron, Analog Devices, ASM International, Bronkhorst, CEA-LETI, Conti Temic, IHP, Infineon Technologies, IPDiA, NXP Semiconductors, Oxford Instruments, R3T, SAFC Hitech, STMicroelectronics, Tyndall National Institute, Eindhoven University of Technology, and University of Helsinki (2009)].

Various ALD processes for $\mathrm{SrTiO}_{3}$ using different Ti and Sr precursors have already been reported. They share the approach of alternating the ALD processes of $\mathrm{TiO}_{2}$ and $\mathrm{SrO}$ in a certain ratio to allow for the control of the film properties of the ternary oxide, such as composition, crystallization temperature, and dielectric constant. ${ }^{5-12}$ The challenge for the STO ALD processes is to optimally tune the material properties within the ALD process windows of $\mathrm{TiO}_{2}$ and $\mathrm{SrO}$. For example, the process temperature is commonly chosen as high as possible to yield the material with lowest impurities levels and best electrical performance. The maximum deposition temperature allowed is, however, limited by the thermal stability of the $\mathrm{Ti}$ and $\mathrm{Sr}$ precursors employed.

A new class of ALD Sr precursors with cyclopentadienyl (Cp) ligands were introduced by Vehkamäki et al. ${ }^{6,7}$ These $\mathrm{Cp}$-based precursors allowed for the thermal ALD with $\mathrm{H}_{2} \mathrm{O}$ at reasonably high temperatures $\left(<300^{\circ} \mathrm{C}\right)$ while providing an adequate vapor pressure. Recently, also Cp-compounds of titanium with improved thermal stability have become available. However, these precursors are not suitable for thermal ALD with $\mathrm{H}_{2} \mathrm{O}$ and require a more reactive oxidant source, such as $\mathrm{O}_{3}$ as reported by Katamreddy et al. ${ }^{8}$

In this paper, we report on the remote plasma ALD process of $\mathrm{SrTiO}_{3}$ using the Cp-compounds Star-Ti [(pentamethylcyclo-

\footnotetext{
* Electrochemical Society Active Member

${ }^{\mathrm{z}}$ E-mail: w.m.m.kessels@tue.nl
}

pentadienyl)trimethoxy-titanium, $\left.\left(\mathrm{CpMe}_{5}\right) \mathrm{Ti}(\mathrm{OMe})_{3}\right]$ and Hyper- $\mathrm{Sr}$ [bis(trisisopropylcyclopentadienyl)-strontium with 1,2-dimethoxyethane adduct, $\left.\operatorname{Sr}\left({ }^{i} \operatorname{Pr}_{3} \mathrm{Cp}\right)_{2} \mathrm{DME}\right]$ as the precursors. During the oxidation step, additional reactivity was provided to the surface chemistry by an $\mathrm{O}_{2}$ plasma. From investigations of the material properties and the optical dielectric function of the films by spectroscopic ellipsometry (SE), the control of film composition by the $[\mathrm{SrO}] /\left[\mathrm{TiO}_{2}\right]$ cycle ratio was demonstrated. A post-deposition anneal was applied to crystallize the STO films, where the optical dielectric function of the film turned out to be a sensitive probe for the onset of crystallization. The electrical performance of the dielectric was evaluated for planar $\mathrm{Pt} / \mathrm{STO} / \mathrm{TiN}$ capacitor test structures.

\section{Experimental}

The remote plasma ALD process of STO was developed in a homebuilt, open-load reactor from the constituent ALD processes of $\mathrm{TiO}_{2}$ and SrO. For these ALD processes, Star-Ti and Hyper-Sr (both from Air Liquide, France) were used as precursors in combination with an $\mathrm{O}_{2}$ plasma ( $>99.999 \%$ purity). The precursors were contained in stainless steel bubblers and they were heated to 110 and $120^{\circ} \mathrm{C}$, resulting in vapor pressures of $\sim 2$ and $\sim 0.5$ Torr for Star-Ti and Hyper-Sr, respectively. The precursor transport to the reactor was facilitated by using Ar bubbling (purity >99.999\%). The precursor delivery lines were set to a temperature $20-30^{\circ} \mathrm{C}$ higher than the bubblers to prevent precursor condensation in the lines. The plasma was generated by a remote inductively coupled plasma source operating at an $\mathrm{O}_{2}$ pressure of $7.5 \mathrm{mTorr}$ with a power of $100 \mathrm{~W}$. The substrates were silicon pieces $(4 \mathrm{~cm}$ $\times 4 \mathrm{~cm}$ ) with native oxide unless otherwise noted. The substrate temperature was $250^{\circ} \mathrm{C}$.

With respect to the ALD STO cycles, it is noted that the $\mathrm{SrO}$ and $\mathrm{TiO}_{2}$ cycles were mixed as completely as possible for each cycle ratio, e.g., an STO cycle with a cycle ratio $[\mathrm{SrO}] /\left[\mathrm{TiO}_{2}\right]=2: 3$ is effectuated by sequentially using the ratios $1: 2$ and $1: 1$.

Thickness and optical constants of the films were determined by SE using J.A. Woollam M2000U (1.25-5.0 eV, in situ) and M2000D (1.25-6.5 eV, ex situ) ellipsometers (J.A. Woollam, Lincoln, Nebraska, USA). The atomic composition and density of the films were determined from the areal density information on the different species, as obtained from the Rutherford backscattering spectroscopy (RBS) measurements using $2 \mathrm{MeV}^{4} \mathrm{He}^{+}$ions. To crystallize the STO films, a post-deposition anneal of $10 \mathrm{~min}$ in $\mathrm{N}_{2}$ was performed at different temperatures starting at $400^{\circ} \mathrm{C}$ and using incremental steps of $50^{\circ} \mathrm{C}$. The maximum annealing temperature was $650^{\circ} \mathrm{C}$. The microstructure of the films was studied by grazing incidence X-ray diffraction at an incident angle of $0.5^{\circ}$ using a Panalytical X'Pert PRO MRD diffractometer (PANalytical B.V., The 

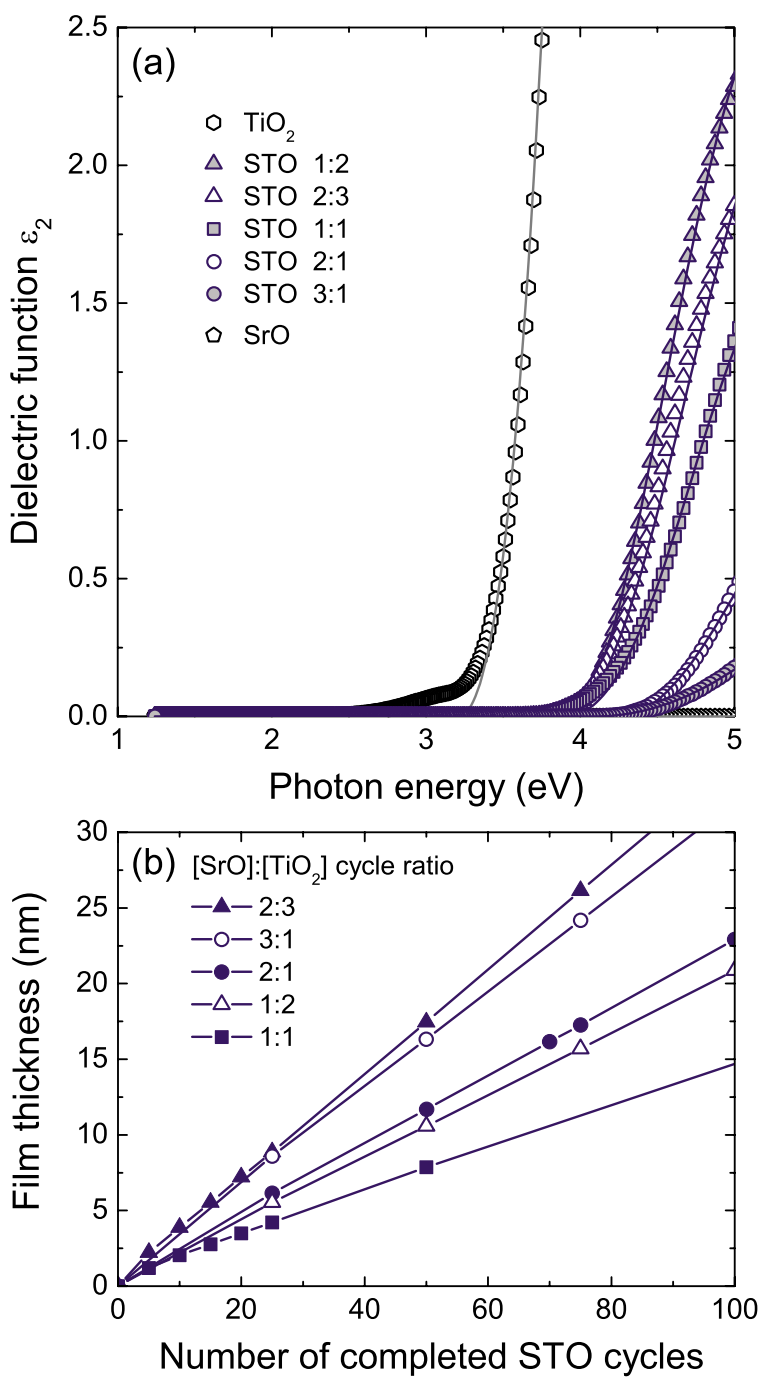

Figure 1. (Color online) Influence of the $[\mathrm{SrO}] /\left[\mathrm{TiO}_{2}\right]$ cycle ratio within the ALD STO cycle on (a) the imaginary part $\left(\varepsilon_{2}\right)$ of the dielectric function of the STO films deposited and (b) the film thickness. The film thickness was extracted from the in situ SE data using the dielectric functions shown in (a). The dielectric functions were parameterized by a B-spline algorithm (symbols) and a single Tauc-Lorentz oscillator model (solid lines, see Table I). The dielectric functions of the $\mathrm{ALD} \mathrm{TiO}_{2}$ and $\mathrm{SrO}$ films are also given.

Netherlands), equipped with a $\mathrm{Cu} \mathrm{K} \alpha$ source providing $1.54 \AA$ radiation. The electrical performance of the films was evaluated using planar capacitor test structures with an area of $\sim 0.5 \times 10^{-3} \mathrm{~cm}^{2}$ that consisted of a $50 \mathrm{~nm}$ thick STO film sandwiched in between Pt top and stoichiometric TiN bottom electrodes prepared by sputtering. The as-deposited films were annealed for $1 \mathrm{~min}$ at $600^{\circ} \mathrm{C}$ in $\mathrm{N}_{2}$, prior to the electrical characterization.

\section{Results and Discussion}

The composition control for the STO films relies on the ability to vary the $[\mathrm{SrO}] /\left[\mathrm{TiO}_{2}\right]$ cycle ratio within the ALD STO cycle. The influence of cycle ratio on the film growth in terms of film thickness and the optical dielectric function of the STO films was studied by monitoring the ALD process using in situ SE. The results are shown in Fig. 1. The optical dielectric functions and film thicknesses of the different STO films were extracted from the SE data by a procedure in which first a B-spline algorithm was used to mathematically extract the dielectric function for every cycle ratio. ${ }^{13}$ Subsequently, the dispersion of the dielectric function was described by a TaucLorentz oscillator parameterization, which is commonly used for semi-transparent films. ${ }^{14}$ The parameters of the parametrizations for different STO films are summarized in Table I. The imaginary part $\left(\varepsilon_{2}\right)$ of the dielectric functions plotted in Fig. 1a shows that the optical constants of the STO films change with the cycle ratio. By employing relatively more $\mathrm{SrO}$ cycles in the STO cycle, a clear transition in the dielectric function is observed from (almost) stoichiometric $\mathrm{SrTiO}_{3}$ toward Sr-rich STO films. This change with cycle ratio is expressed by a gradual decrease in the refractive index and increase in optical bandgap toward the properties of pure SrO.

Figure $1 \mathrm{~b}$ shows the film thickness as a function of completed STO cycles for the different cycle ratios used. The increase in the film thickness is linear in the number of cycles for all cycle ratios, and the extrapolation of the linear dependence to zero film thickness suggests that all the STO films show no significant nucleation delay on the native oxide Si substrates. From the slopes of the lines in Fig. $1 \mathrm{~b}$, the growth per completed STO cycle for the different cycle ratios were calculated. Obviously, these slopes are directly related to the number of $\mathrm{SrO}$ and $\mathrm{TiO}_{2}$ constituent cycles within the STO cycle. Therefore, the corresponding growth per cycle (GPC) values were calculated by dividing the growth per completed STO cycle by the total amount of constituent $\mathrm{SrO}$ and $\mathrm{TiO}_{2}$ cycles within the STO cycle. These growth per cycle values are presented in Table II which summarizes properties of the STO films deposited using different cycle ratios. The results in this table as well as the difference in dielectric functions in Fig. 1a clearly demonstrate the ability to control the film composition with the $[\mathrm{SrO}] /\left[\mathrm{TiO}_{2}\right]$ cycle ratio.

Before discussing the results in Table II more extensively, first the self-limiting nature of the remote plasma ALD STO process is addressed from measurements of the growth per cycle for varying dosing conditions using in situ SE. A similar approach as described in Ref. 14 was used, i.e., one of the parameters (Star-Ti dosing time, Hyper-Sr dosing time, or $\mathrm{O}_{2}$ plasma exposure time) was varied, while the other parameters were set to their saturation values. The plasma exposure time was equal for both the $\mathrm{SrO}$ and $\mathrm{TiO}_{2}$ cycles. After the precursor dosing times, the chamber was purged by Ar for $12 \mathrm{~s}$ at a pressure of $7.5 \mathrm{mTorr}$, followed by an evacuation step of $5 \mathrm{~s}$. After the plasma exposure, the chamber was purged by $\mathrm{O}_{2}$ for $1 \mathrm{~s}$, followed by an evacuation step of $3 \mathrm{~s}$. As illustrated in Fig. 2 for the cycle ratio of $[\mathrm{SrO}] /\left[\mathrm{TiO}_{2}\right]=1: 1$, the growth per completed STO cycle clearly saturated for dosing times of Star-Ti of $5 \mathrm{~s}$, Hyper-Sr of $30 \mathrm{~s}$, and $\mathrm{O}_{2}$ plasma exposure of $5 \mathrm{~s}$. Pure $\mathrm{SrO}\left(\mathrm{TiO}_{2}\right)$ was deposited when using $0 \mathrm{~s}$ of $\mathrm{Ti}(\mathrm{Sr})$ precursor dosing in the ALD STO cycle, which results in the fact that the saturation curves do not start at the origin in Figs. $2 a$ and $2 b$ (as is the case for ALD processes of binary metal oxides). The combination of Hyper-Sr and $\mathrm{O}_{2}$ plasma leads to clear saturation, which was not observed for the thermal ALD using $\mathrm{H}_{2} \mathrm{O}$. The latter was attributed to the accumulation of the $\mathrm{Sr}$ precursor and $\mathrm{H}_{2} \mathrm{O}$ in the reactor. ${ }^{5}$ It is noted that the same dosing times were found to result in saturation for the constituent $\mathrm{SrO}$ and $\mathrm{TiO}_{2}$ ALD processes (not shown). Although not explicitly tested, it is therefore expected that saturation was also achieved when employing other cycle ratios. The abovementioned times for precursor dosing, plasma exposure, purging, and reactor evacuation were used for all STO films reported in this work. The only exception is that a $\mathrm{Sr}$ precursor dosing time of $15 \mathrm{~s}$ instead of $30 \mathrm{~s}$ was chosen for the films listed in Table II in order to shorten the cycle time. This resulted in a slightly reduced growth per completed STO cycle of $0.14 \pm 0.01 \mathrm{~nm} /$ cycle (cf., Table II) compared to the value observed in Fig. 2.

Table II shows that the STO films were all Sr-rich for the cycle ratios investigated and that the atomic density decreased with increasing Sr content in the STO films. Almost stoichiometric $\mathrm{SrTiO}_{3}$ was deposited using a cycle ratio of 1:2. The amount of oxygen in the STO films was approximately 60 atom $\%$ and related well to the expected value with respect to the $\mathrm{Sr}$ and Ti contents in the film. The only exception was the STO film deposited using cycle ratio of 3:1 that showed a slightly higher oxygen concentration. The STO films contained fluorine contamination $(<10$ atom \%) that probably origi- 
Table I. Model parameters of the optical parameterizations used to describe the optical dielectric function of the remote plasma ALD STO films (in the range of 1.25-5.0 eV) with different composition and microstructure. The STO films were described by a single Tauc-Lorentz oscillator, while a double Tauc-Lorentz oscillator model and a Cauchy model were applied for $\mathrm{TiO}_{2}$ and $\mathrm{SrO}$, respectively. The STO films with $[\mathrm{Sr}] /[\mathrm{Ti}]=1.3\left([\mathrm{SrO}] /\left[\mathrm{TiO}_{2}\right]=2: 3\right)$ used in the annealing study were parameterized in an extended energy range $(1.25-6.5 \mathrm{eV})$ by two Tauc-Lorentz oscillators for the as-deposited film and three Tauc-Lorentz oscillators for the $650^{\circ} \mathrm{C}$ annealed film. The parameters are defined as specified in Ref. 13 .

\begin{tabular}{|c|c|c|c|c|c|c|c|c|}
\hline \multicolumn{9}{|c|}{ Tauc-Lorentz model } \\
\hline $\begin{array}{c}\text { Cycle ratio } \\
{[\mathrm{SrO}] /\left[\mathrm{TiO}_{2}\right]}\end{array}$ & $\begin{array}{l}\text { Thickness } \\
\text { (nm) }\end{array}$ & $x^{2}$ & $\begin{array}{c}A_{j} \\
(\mathrm{eV})\end{array}$ & $\begin{array}{l}E_{0 j} \\
(\mathrm{eV})\end{array}$ & $\begin{array}{c}\Gamma_{j} \\
(\mathrm{eV})\end{array}$ & $\begin{array}{c}E_{g j} \\
(\mathrm{eV})\end{array}$ & $\varepsilon_{\infty}$ & $\begin{array}{c}A_{p} \\
\left(\mathrm{eV}^{2}\right)\end{array}$ \\
\hline \multirow[t]{2}{*}{$0: 1$} & $30.2 \pm 0.5$ & 6 & 204 & 4.15 & 1.38 & 3.21 & 1 & - \\
\hline & & & 208 & 4.7 & 11 & 4.1 & & \\
\hline $1: 2$ & 30.8 & 9 & 149 & 4.5 & 2.4 & 3.9 & 1 & 154 \\
\hline $2: 3$ & 34.7 & 8 & 98 & 4.9 & 2.6 & 3.9 & 1 & 160 \\
\hline $1: 1$ & 31.2 & 9 & 64 & 4.9 & 2.3 & 3.9 & 1 & 186 \\
\hline $2: 1$ & 34.0 & 11 & 88 & 5.4 & 4.7 & 4.3 & 2.1 & - \\
\hline $3: 1$ & 32.0 & 6 & 71 & 8.7 & 5.7 & 4.1 & 1 & - \\
\hline \multicolumn{9}{|c|}{ Cauchy model } \\
\hline & $\begin{array}{l}\text { Thickness } \\
\text { (nm) }\end{array}$ & $\chi^{2}$ & $A_{n}$ & & $\begin{array}{c}B_{n} \\
\left(\mu \mathrm{m}^{2}\right)\end{array}$ & & $\begin{array}{c}C_{n} \\
\left(\mu \mathrm{m}^{4}\right)\end{array}$ & \\
\hline \multirow[t]{3}{*}{$1: 0$} & 10.9 & 2 & 1.51 & & $1.07 \times 10^{-2}$ & & $1.2 \times 10^{-4}$ & \\
\hline & \multicolumn{3}{|c|}{ Tauc-Lorentz model } & & & & & \\
\hline & $\begin{array}{l}\text { Thickness } \\
\text { (nm) }\end{array}$ & $x^{2}$ & $\begin{array}{c}A_{j} \\
(\mathrm{eV})\end{array}$ & $\begin{array}{l}E_{0 j} \\
(\mathrm{eV})\end{array}$ & $\begin{array}{c}\Gamma_{j} \\
(\mathrm{eV})\end{array}$ & $\begin{array}{l}E_{g j} \\
(\mathrm{eV})\end{array}$ & $\varepsilon_{\infty}$ & $\begin{array}{c}A_{p} \\
\left(\mathrm{eV}^{2}\right)\end{array}$ \\
\hline \multirow{5}{*}{$\begin{array}{c}2: 3 \\
\text { as-deposited } \\
2: 3 \\
\text { annealed at } 650{ }^{\circ} \mathrm{C}\end{array}$} & 37.1 & 11 & 109 & 4.73 & 1.45 & 4.19 & 1.8 & - \\
\hline & & & 18 & 7.57 & 2.33 & 2.86 & & \\
\hline & 28.2 & 9 & 125 & 4.30 & 0.94 & 3.49 & 1.6 & - \\
\hline & & & 300 & 4.67 & 0.83 & 4.48 & & \\
\hline & & & 293 & 5.89 & 1.63 & 5.89 & & \\
\hline
\end{tabular}

nated from the outgassing of the Teflon seals in the valves of the bubbler that were heated at $120^{\circ} \mathrm{C}$. These $\mathrm{F}$ impurities can, however, have a positive effect on the electrical performance of the films by $\mathrm{F}$ passivation of oxygen vacancies and interface traps. ${ }^{16}$ The RBS measurements were not sensitive enough to detect carbon impurities; however, ex situ infrared transmission absorbance spectra revealed the presence of $\mathrm{CO}_{x}$-related species in the films. The relative amount of these carbonate species increased with $\mathrm{Sr}$ content in the STO films. As no capping layer was deposited onto the STO films prior to the infrared measurements, it is unclear whether the carbonate species were formed during deposition or after exposure to the ambient. The mass density of the STO films was $4.1 \pm 0.1 \mathrm{~g} \mathrm{~cm}^{-3}$ and showed no trend with the cycle ratio. This density is similar to the one reported by Popovici et al., ${ }^{5}$ both being lower than the bulk density of $\mathrm{SrTiO}_{3}\left(5.1 \mathrm{~g} \mathrm{~cm}^{-3}\right.$, Ref. 15).

The saturated growth per completed ALD cycle of $0.16 \pm 0.01 \mathrm{~nm}$ is higher than those reported in the literature for similar cycle ratio of $[\mathrm{SrO}] /\left[\mathrm{TiO}_{2}\right]=1: 1$ and deposition temperature of $250^{\circ} \mathrm{C}$ : $0.07 \mathrm{~nm}$ using $\mathrm{Ti}\left(\mathrm{O}{ }^{i} \mathrm{Pr}\right)_{4}, \operatorname{Sr}\left({ }^{i} \mathrm{Pr}_{3} \mathrm{Cp}\right)_{2}$, and $\mathrm{H}_{2} \mathrm{O}$, $0.11 \mathrm{~nm}$ using $\mathrm{Ti}(\mathrm{OMe})_{4}, \mathrm{Sr}\left({ }^{t} \mathrm{Bu}_{3} \mathrm{Cp}\right)_{2}$, and $\mathrm{H}_{2} \mathrm{O}$, ${ }^{5}$ and $0.12 \mathrm{~nm}$ using $\mathrm{Ti}\left(\mathrm{O}{ }^{i} \mathrm{Pr}\right)_{4}, \mathrm{Sr}(\mathrm{thd})_{2}$, and $\mathrm{H}_{2} \mathrm{O}$ plasma. ${ }^{9}$ It should be noted that these various ALD processes yielded (slightly) different compositions of the STO films. For the current process, the compositional ratio was $[\mathrm{Sr}] /[\mathrm{Ti}]=1.5$ (cf., Table II), whereas STO films with $[\mathrm{Sr}] /[\mathrm{Ti}]=1.2$ were obtained by Vehkamäki et al., ${ }^{7}[\mathrm{Sr}] /[\mathrm{Ti}]$ $=0.85$ by Popovici et al., ${ }^{5}$ and $[\mathrm{Sr}] /[\mathrm{Ti}]=1.0$ by Kwon et al. ${ }^{9}$ Furthermore, when varying the deposition temperature in the range $150-300^{\circ} \mathrm{C}$, the growth per completed STO cycle was found constant at $0.15 \pm 0.01 \mathrm{~nm}$, while it increased to $0.18 \pm 0.01 \mathrm{~nm}$ at $350^{\circ} \mathrm{C}$. The latter is attributed to a slight decomposition of Hyper-Sr. ${ }^{8}$

As mentioned, the GPC values in Table II represent the growth per completed STO cycle divided by the total amount of constituent

Table II. Influence of the $[\mathrm{SrO}] /\left[\mathrm{TiO}_{2}\right]$ cycle ratio on the GPC and the material properties of the STO films. The thicknesses were $11 \mathrm{~nm}$ for the $\mathrm{SrO}$ film and $\sim 30 \mathrm{~nm}$ for the $\mathrm{STO}$ and $\mathrm{TiO}_{2}$ films. The relative errors in the atomic density are $3 \%$ for $\mathrm{Sr}, \mathrm{Ti}$, and $\mathrm{O}$ and $10 \%$ for $\mathrm{F}$ and H. Typical absolute errors for the other data are given in the first row.

\begin{tabular}{|c|c|c|c|c|c|c|c|c|c|c|c|}
\hline $\begin{array}{l}\text { Cycle ratio } \\
{[\mathrm{SrO}] /\left[\mathrm{TiO}_{2}\right]}\end{array}$ & $\begin{array}{l}\text { Thickness } \\
(\mathrm{nm})\end{array}$ & $\begin{array}{l}\text { GPC } \\
(\mathrm{nm})\end{array}$ & $\begin{array}{c}{[\mathrm{Sr}] /[\mathrm{Ti}]} \\
\text { ratio }\end{array}$ & $\mathrm{Sr}$ & $\mathrm{Ti}$ & $\begin{array}{c}\text { Aton } \\
(10 \\
\mathrm{O}\end{array}$ & $\begin{array}{c}\text { densi } \\
\left.\mathrm{m}^{-3}\right) \\
\mathrm{F}\end{array}$ & $\mathrm{H}$ & Total & $\begin{array}{l}\text { Refractive } \\
\text { index }\end{array}$ & $\begin{array}{l}\text { Bandgap } \\
(\mathrm{eV})\end{array}$ \\
\hline $0: 1$ & $30.2 \pm 0.5$ & $0.054 \pm 0.005$ & 0 & - & 2.8 & 5.7 & - & 0.1 & 8.6 & $2.44 \pm 0.02$ & $3.33 \pm 0.05$ \\
\hline $1: 2$ & 30.8 & 0.068 & 1.1 & 1.3 & 1.3 & 3.9 & 0.4 & 0.2 & 7.0 & 1.91 & 3.91 \\
\hline $2: 3$ & 34.7 & 0.069 & 1.3 & 1.5 & 1.1 & 3.7 & 0.1 & 0.2 & 6.6 & 1.87 & 3.90 \\
\hline $1: 1$ & 31.2 & 0.069 & 1.5 & 1.5 & 1.0 & 3.5 & 0.8 & 0.2 & 7.0 & 1.82 & 3.96 \\
\hline $2: 1$ & 34 & 0.074 & 2.8 & 1.5 & 0.5 & 2.5 & 0.5 & 0.2 & 5.2 & 1.70 & 4.25 \\
\hline $3: 1$ & 32 & 0.078 & 4.0 & 1.5 & 0.4 & 3.1 & 0.2 & 0.3 & 5.5 & 1.63 & 4.20 \\
\hline $1: 0$ & 10.9 & 0.051 & - & - & - & - & - & - & $5.9^{\mathrm{a}}$ & 1.53 & $>5$ \\
\hline
\end{tabular}

${ }^{a}$ Calculated for SrO from the bulk mass density of $5.1 \mathrm{~g} \mathrm{~cm}^{-3} .{ }^{16}$ 

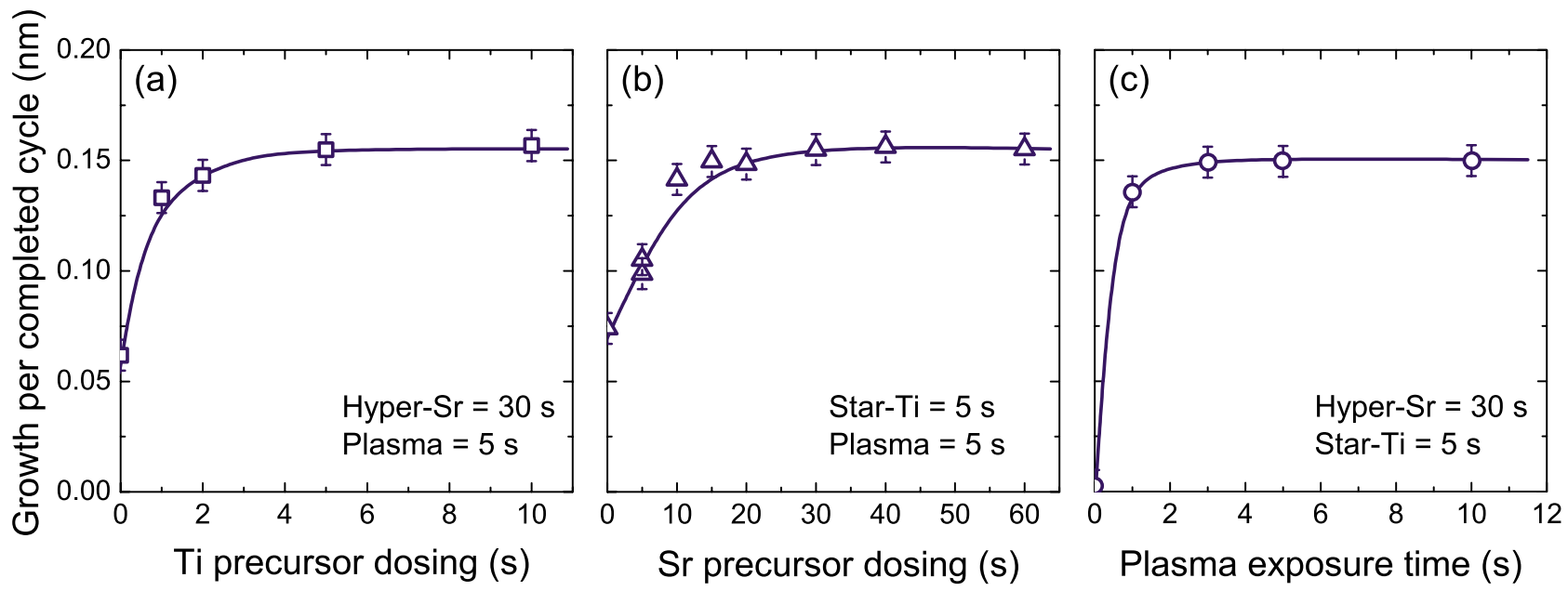

Figure 2. (Color online) Growth per completed STO cycle as a function of the ALD process parameters: (a) Star-Ti dosing time, (b) Hyper-Sr dosing time, and (c) $\mathrm{O}_{2}$ plasma exposure time. During the variation of one of these parameters, the other times were set to their saturation values as indicated. The STO film was deposited at $250^{\circ} \mathrm{C}$ using a cycle ratio $[\mathrm{SrO}] /\left[\mathrm{TiO}_{2}\right]=1: 1$ and the growth per cycle values were determined by in situ $\mathrm{SE}$. The lines serve as guides to the eye.

$\mathrm{TiO}_{2}$ and $\mathrm{SrO}$ cycles used. Insight into these $\mathrm{GPC}$ values can be obtained by evaluating the GPC values of the ALD processes of $\mathrm{TiO}_{2}$ and $\mathrm{SrO}$. The combination of Star-Ti precursor and $\mathrm{O}_{2}$ plasma resulted in a high GPC of $0.054 \pm 0.005 \mathrm{~nm}$ compared to the $0.03 \mathrm{~nm}$ reported for Star-Ti and $\mathrm{O}_{3},{ }^{8} 0.04 \mathrm{~nm}$ using $\mathrm{Ti}(\mathrm{OMe})_{4}$ and $\mathrm{H}_{2} \mathrm{O}$, ${ }^{5}$ and $0.03-0.05 \mathrm{~nm}$ using $\mathrm{Ti}\left(\mathrm{O}{ }^{i} \mathrm{Pr}\right)_{4}$ and $\mathrm{H}_{2} \mathrm{O}$. ${ }^{7,11}$ The combination of Hyper-Sr and an $\mathrm{O}_{2}$ plasma resulted in a GPC of $0.051 \pm 0.005 \mathrm{~nm}$ that relates well to the $0.05-0.06 \mathrm{~nm}$ reported for $\mathrm{Sr}\left({ }^{t} \mathrm{Bu}_{3} \mathrm{Cp}\right)_{2}$ and $\mathrm{H}_{2} \mathrm{O},{ }^{5} \mathrm{Sr}(\mathrm{dpm})_{2}$ and $\mathrm{O}_{2}$ plasma, ${ }^{12}$ and $\mathrm{Sr}(\text { thd })_{2}$ and $\mathrm{O}_{3}{ }^{11}$ This GPC value exceeds the $0.01-0.02 \mathrm{~nm}$ reported for $\mathrm{Sr}(\text { thd })_{2}$ and $\mathrm{H}_{2} \mathrm{O}$ (Ref. 10) or $\mathrm{H}_{2} \mathrm{O}$ plasma. ${ }^{9}$ The GPC for SrO obtained is, however, less than $\sim 0.1 \mathrm{~nm}$ reported for Hyper-Sr with $\mathrm{H}_{2} \mathrm{O}$ or $\mathrm{O}_{3},{ }_{7,8}$ despite the fact that the $\mathrm{O}_{2}$ plasma is considered as the stronger oxidizing agent (as evident for the ALD process of $\mathrm{TiO}_{2}$ using Star-Ti).

Interestingly, the GPC during the STO process is higher than expected from the sum of the GPC values of the $\mathrm{TiO}_{2}$ and $\mathrm{SrO}$ processes (cf., Table II). Moreover, the GPC increased with the Sr content in the STO film, which can be attributed to the decreasing atomic density of the films. The $\mathrm{Sr}$ and $\mathrm{Ti}$ areal densities from RBS (not shown) suggest that more $\mathrm{Sr}$ precursor adsorbed on a $\mathrm{TiO}_{2}$ surface relative to a $\mathrm{SrO}$ surface. Also other ALD STO processes showed an increased GPC, and different explanations have been given. Both Popovici et al. and Kosola et al. observed an increased growth per STO cycle with Sr content, but related this to either an enhanced adsorption of the $\mathrm{Ti}(\mathrm{OMe})_{4}$ precursor on $\mathrm{SrO}$ (Ref. 5) or a reduced adsorption of the $\mathrm{Sr}(\mathrm{thd})_{2}$ precursor on $\mathrm{TiO}_{2} .{ }^{11}$ Conversely, using the same precursors as Kosola et al. but using $\mathrm{H}_{2} \mathrm{O}$ instead of $\mathrm{O}_{3}$, Kwon et al. observed an increased GPC with Ti content in the STO films and related this to an increased $\mathrm{Sr}(\text { thd })_{2}$ adsorption on the $\mathrm{TiO}_{2}$ surface. ${ }^{10}$ Apparently, the combination of precursors and oxidant sources employed has a strong effect on the $\mathrm{Sr}$ and Ti incorporation into the STO films. This aspect will be addressed in more detail in future work. ${ }^{17}$

The as-deposited amorphous STO films need to be crystallized to reach ultrahigh- $k$ values and, therefore, the effect of post-deposition annealing was studied for films deposited on native oxide Si substrates. The Sr-rich STO films with $[\mathrm{Sr}] /[\mathrm{Ti}]=1.3$ are considered the most interesting, because an excess of $\mathrm{Sr}$ in the film was reported to reduce the capacitor leakage without compromising too much on the $k$-value. ${ }^{5}$ Figure 3 shows the influence of the annealing temperature on the microstructure and optical dielectric function of this Sr-rich STO film. For annealing temperatures up to $450^{\circ} \mathrm{C}$, the films remained amorphous and the optical dielectric function re- mained unchanged. However, after annealing up to $500^{\circ} \mathrm{C}$, the optical dielectric function changed drastically (Fig. 3b) and several diffraction peaks appeared (Fig. 3a), indicating that the films crystallized. Using higher annealing temperatures hardly affected the diffraction spectrum and the optical dielectric function remained relatively unchanged, which likely indicates an almost full crystallization of the film at $500^{\circ} \mathrm{C}$. The diffraction peaks of the STO film point to the formation of cubic $\mathrm{SrTiO}_{3}$ with a perovskite structure, as is evident from the agreement with the (110), (111), (200), and (211) peaks of the $\mathrm{SrTiO}_{3}$ powder spectrum. ${ }^{19}$ The formation of cubic $\mathrm{SrTiO}_{3}$ phase after anneal was also reported for other ALD processes. ${ }^{5-7,12}$ For the STO films with other compositions (not shown), the dielectric functions also changed considerably for annealing temperatures higher than $500-550^{\circ} \mathrm{C}$. Popovici et al. reported a higher crystallization temperature of $540-570^{\circ} \mathrm{C}$, but that can likely be related to the thinner STO films $(\sim 7 \mathrm{~nm})$ and shorter annealing times $(1 \mathrm{~min})$ employed in their study. ${ }^{5}$ Note that in the present study the post-deposition anneal was carried out at different temperatures (using incremental steps $50^{\circ} \mathrm{C}$, see Fig. 3) and using an annealing time of $10 \mathrm{~min}$ per temperature.

The thickness of the STO films was found to decrease by about $15 \%$ after crystallization. This film shrinkage can lead to microcracks in the film ${ }^{10}$ as was also observed for the current films in a preliminary study. It has been reported that crack formation can be suppressed by the method of in situ crystallization using a thin crystallized STO seed layer. ${ }^{19}$

The optical dielectric function of the annealed STO showed a good resemblance to that of crystalline STO reported by Zollner et al. ${ }^{20}$ After annealing to $650^{\circ} \mathrm{C}$, the dielectric function was parameterized using three Tauc-Lorentz oscillators (see Table II). Upon annealing, the refractive index increased to $2.2 \pm 0.1$ (at $1.96 \mathrm{eV}$ ), and the Tauc optical band-gap decreased to $3.6 \pm 0.1 \mathrm{eV}$. These values relate well to the refractive index of 1.9-2.4 for crystalline $\mathrm{SrTiO}_{3}$ films, ${ }^{5,20}$ while the band-gap is slightly higher than the direct bandgap of $3.4 \mathrm{eV}$ of $\mathrm{SrTiO}_{3}{ }^{20}$

As an initial experiment, the electrical performance of $50 \mathrm{~nm}$ thick STO films with $[\mathrm{Sr}] /[\mathrm{Ti}]=1.3$ was evaluated for planar Pt/ STO/TiN capacitor structures. The STO film had a high permittivity of $k>80$, which is comparable to the $k=90$ of similar Sr-rich STO films obtained by thermal ALD using Cp-based precursors. 5,6 The leakage current of the films (with an EOT of $<2.4 \mathrm{~nm}$ ) was $\sim 1 \times 10^{-7}$ and $\sim 6 \times 10^{-9} \mathrm{~A} / \mathrm{cm}^{2}$ for top and bottom electrode injections, respectively, when $1 \mathrm{~V}$ was applied over the capacitor. 

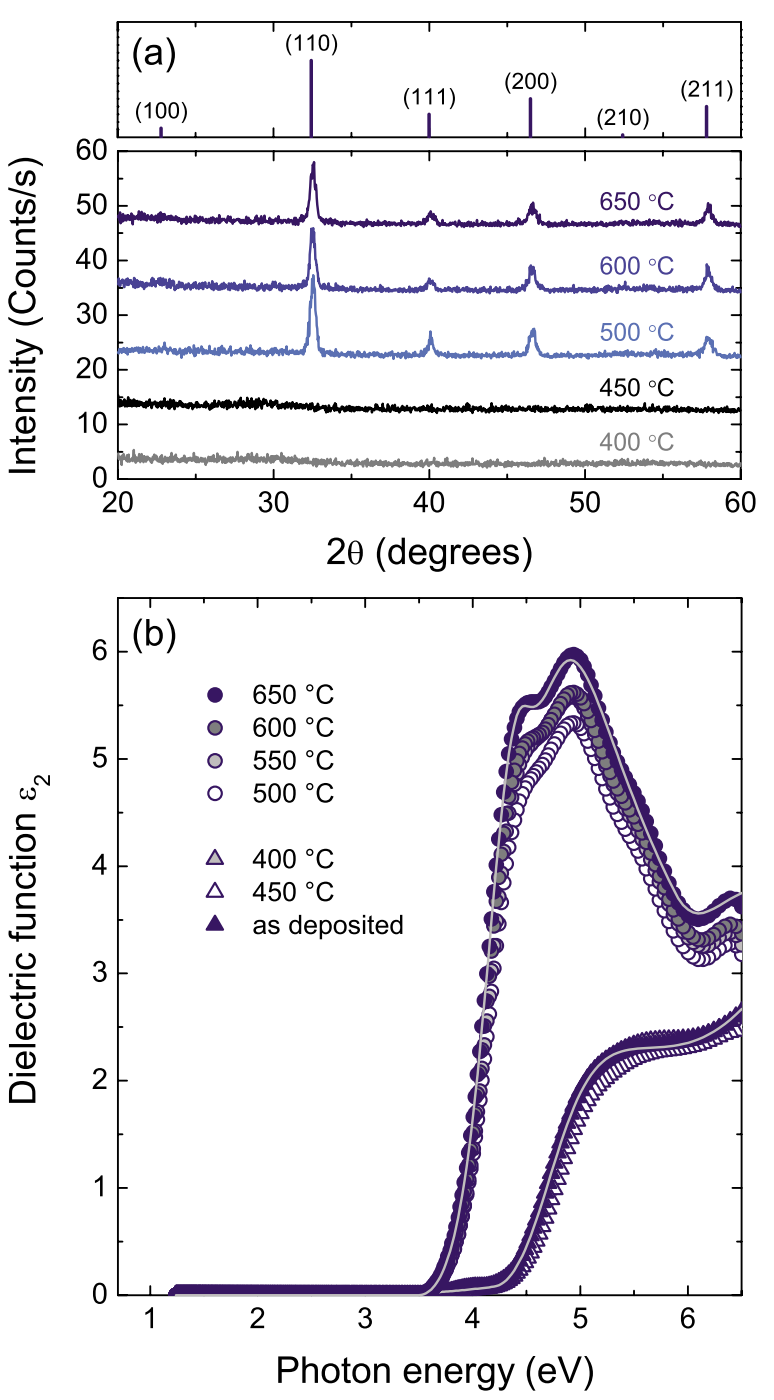

Figure 3. (Color online) Effect of the annealing temperature during postdeposition anneal on (a) the XRD spectrum and (b) the imaginary part $\left(\varepsilon_{2}\right)$ of the dielectric function of an STO film with $[\mathrm{Sr}] /[\mathrm{Ti}]=1.3$. The XRD spectra are offset vertically for clarity and the diffraction spectrum of a cubic $\mathrm{SrTiO}_{3}$ powder sample is shown as taken from Ref. 18 The dielectric functions were obtained by ex situ SE and were parameterized by a B-spline algorithm (symbols) and Tauc-Lorentz oscillator model (solid lines, $T$ $\leqslant 450^{\circ} \mathrm{C}$ : two oscillators and $T \geqslant 500^{\circ} \mathrm{C}$ : three oscillators, see Table I). Note that the dielectric functions for " $450^{\circ} \mathrm{C}$ " and " $550^{\circ} \mathrm{C}$ " overlap the ones for "as-deposited" and " $600^{\circ} \mathrm{C}$," respectively.

These leakage currents are relatively low compared to the values of $\sim 10^{-6} \mathrm{~A} / \mathrm{cm}^{2}$ for similar films with EOT values of $0.68 \mathrm{~nm}$ (Ref. 5) and $17.3 \mathrm{~nm}$ (Ref. 6).

To further assess the electrical performance of the remote plasma ALD STO films, additional characterization will be required. The data need to be extended to different capacitor structures with other electrode materials and to high-aspect ratio structures, while the influence of electrode material on the crystallization behavior of the STO films should also be addressed. For this purpose, it was already established in this work that the STO film growth lead to a substrateindependent GPC with no significant nucleation delay on $\mathrm{Pt}, \mathrm{Ru}$, $\mathrm{RuO}_{2}, \mathrm{TaN}$, and TiN substrates which are considered as potential capacitor electrode materials.

\section{Conclusions}

A remote plasma ALD process for the deposition of ultrahigh- $k$ $\mathrm{SrTiO}_{3}$ films was developed using Cp-based Ti and $\mathrm{Sr}$ precursors in combination with $\mathrm{O}_{2}$ plasma to provide additional reactivity over thermal ALD processes. The film growth was monitored by spectroscopic ellipsometry yielding accurate thickness information, whereas the optical dielectric function turned out to be a sensitive probe for the composition and microstructure of the $\mathrm{SrTiO}_{3}$ films. The $\mathrm{SrTiO}_{3}$ film properties, such as atomic composition, density, and refractive index, were found to be governed by the $[\mathrm{SrO}] /\left[\mathrm{TiO}_{2}\right]$ cycle ratio. The as-deposited films were amorphous and crystallized after post-deposition anneal at $500^{\circ} \mathrm{C}$. Electrical characterization of the $\mathrm{SrTiO}_{3}$ films with $[\mathrm{Sr}] /[\mathrm{Ti}]=1.3$ in planar capacitor structures revealed a high dielectric constant $k>80$ and low leakage current of $<1 \times 10^{-7}$ at $1 \mathrm{~V}$.

\section{Acknowledgments}

Dr. A. Zauner (Air Liquide) is thanked for supplying the precursors. Dr. W. F. A. Besling, Dr. A. L. Roest (both NXP Semiconductors), Dr. Ch. Wenger (IFX), and Dr. G. Ruhl (Infineon) are acknowledged for performing the electrical characterization. W. Keuning (TU/e) is thanked for performing the XRD measurements. This work is supported by the Dutch Technology Foundation STW and is carried out as part of the MaxCaps project (2T210) within the European Medea+ framework

Eindhoven University of Technology assisted in meeting the publication costs of this article.

\section{References}

1. International Technology Roadmap for Semiconductors (2009). http:// public.itrs.net, last accessed: August 1, 2010.

2. S. K. Kim, S. W. Lee, J. H. Han, B. Lee, S. Han, and C. S. Hwang, Adv. Funct. Mater, 20, 2989 (2010).

3. J. A. Kittl, K. Opsomer, M. Popovici, N. Menou, B. Kaczer, X. P. Wang, C. Adelmann, M. A. Pawlak, K. Tomida, A. Rothschild, et al., Microelectron. Eng., 86, 1789 (2009).

4. S. van Elshocht, C. Adelmann, S. Clima, G. Pourtois, T. Conard, A. Delabie, A. Franquet, P. Lehnen, J. Meersschaut, N. Menou, et al., J. Vac. Sci. Technol. B, 27, 209 (2009).

5. M. Popovici, S. van Elshocht, N. Menou, J. Swerts, D. Pierreux, A. Delabie, B. Brijs, T. Conard, K. Opsomer, J. W. Maes, et al., J. Electrochem. Soc., 157, G1 (2009).

6. M. Vehkamäki, T. Hatanpää, T. Hänninen, M. Ritala, and M. Leskelä, Electrochem. Solid-State Lett., 2, 504 (1999).

7. M. Vehkamäki, T. Hänninen, M. Ritala, M. Leskelä, T. Sajavaara, E. Rauhala, and J. Keinonen, Chem. Vap. Deposition, 7, 75 (2001).

8. R. Katamreddy, V. Omarjee, B. Feist, C. Dussarat, M. Singh, and C. Takoudis, ECS Trans., 16(5), 487 (2008).

9. O. S. Kwon, S. K. Kim, M. Cho, C. S. Hwang, and J. Jeong, J. Electrochem. Soc., 152, C229 (2005).

10. O. S. Kwon, S. W. Lee, J. H. Han, and C. S. Hwang, J. Electrochem. Soc., 154, G127 (2007)

11. A. Kosola, M. Putkonen, L. S. Johansson, and L. Niinistö, Appl. Surf. Sci., 211, $102(2003)$.

12. J. H. Ahn, S. W. Kang, J. Y. Kim, J. H. Kim, and J. S. Roh, J. Electrochem. Soc., 155, G185 (2008).

13. J. W. Weber, T. A. R. Hansen, M. C. M. van de Sanden, and R. Engeln, J. Appl. Phys., 106, 123503 (2009).

14. E. Langereis, S. B. S. Heil, H. C. M. Knoops, W. Keuning, M. C. M. van de Sanden, and W. M. M. Kessels, J. Phys. D, 42, 073001 (2009).

15. D. R. Lide and W. M. Haynes, Handbook of Chemistry and Physics, 90th ed., CRC Press, Boca Raton (2010).

16. Y.-T. Chen, H. Zhao, J. H. Yum, Y. Wang, F. Xue, F. Zhou, and J. C. Lee, J. Electrochem. Soc., 157, G71 (2010).

17. S. D. Elliott, A. Zydor, E. Langereis, and W. M. M. Kessels, Proceedings of the 10th International Conference on Atomic Layer Deposition (American Vacuum Society, New York, 2010).

18. Powder Diffraction File, Card No 35-0734, International Center for Diffraction Data, Newton Square, PA

19. S. W. Lee, O. S. Kwon, J. H. Han, and C. S. Hwang, Appl. Phys. Lett., 92, 222903 (2008).

20. S. Zollner, A. A. Demkov, R. Liu, P. L. Fejes, R. B. Gregory, P. Alluri, J. A. Curless, Z. Yu, J. Ramdani, and R. Droopad, J. Vac. Sci. Technol. B, 18, 2242 (2000). 